\title{
Appeals to Science: Recirculation of Online Claims in Socioscientific Reasoning
}

\author{
Anne Solli ${ }^{1}$ \\ Published online: 20 July 2019 \\ (C) The Author(s) 2019
}

\begin{abstract}
Conflicting knowledge claims regarding complex issues have become readily available through networked digital media, and the introduction of Internet access to classrooms has provided opportunities for accessing a huge number of sources. Science education plays an important role in providing students opportunities to seek and evaluate information and engage in reasoning. The aim of this article is to analyze ways upper secondary science students invoke recirculated online claims originating from a scientific paper in conversations regarding genetically modified organisms (GMO), and to understand how such invocations are effective in order for students to engage accountably. By using the notion of communicative activity types - the meaning and function of the recirculated claims were analyzed in (1) a peer discussion, (2) a debate, and (3) a reflective seminar. The persuasive power of the discursive resource "appeals to science" is illustrated when students enlist scientific objectivity and rigor to underpin the credibility of arguments in a debate, and when qualifying a reflective position in a seminar, whereas they reflect on how actors in a Web context use appeals to science rhetorically when engaged in a discussion with peers reporting online claims. The study offers insight into kinds of communicative competences involved in conversations and how "scientific facts" justify, in this case, opposition to GMO. Finally, it is reflected upon the importance of not only learning how to make well-founded knowledge claims, but also to understand how science is used rhetorically in order to develop appropriate responses to complex issues in the digital age.
\end{abstract}

Keywords Controversy mapping · Socioscientific issues (SSIs) - Appeals to science · Communicative activity types (CATs) · Genetically modified organisms (GMOs)

Anne Solli

anne.solli@gu.se

1 Institution for Learning, Communication and Education, University of Gothenburg, Box 100, S-405 30 Gothenburg, Sweden 


\section{Introduction}

The Internet has become the dominant medium through which the public access knowledge and information in all areas and disciplines (Hodson 2011). It offers a vast array of useful and contradictory claims and arguments from a multiplicity of sources including conflicting knowledge claims from different actors and fields. The ability to navigate and critically reflect on the content and services available via information and communication technologies becomes ever more important. This requires us to be able to select and evaluate the sources of information, as well as the information itself, which requires new and complex skills (Mason et al. 2018).

Students need support in making sense of websites and their information (Mason et al. 2011); the media literacy field has developed frameworks for examining Internet media use in education but the more traditional content disciplines such as science education have been reported to be slow to respond to this challenge (Klosterman et al. 2012). In schools, conducting online searching tasks has become a routine activity for identifying and accessing information on a wide variety of topics including so-called socioscientific issues (SSIs) such as vaccinations, nuclear energy, or genetically modified organisms (GMOs) (Hsu et al. 2014; Tsai 2018). The curricula in many jurisdictions require schools to address issues of information and scientific literacies, and educational institutions are faced with the challenge of helping students develop the competences to constructively handle complex and controversial issues encountered online (Almqvist and Östman 2006; Furberg and Ludvigsen 2008).

It is taken for granted, and seems intuitively reasonable, that informed decisions on SSIs draw on science (Zeidler et al. 2009; Zeidler et al. 2005). However, it is unclear what it means to successfully invoke scientific knowledge in socioscientific deliberations, not least since the theoretical perspectives through which SSI reasoning is understood differ. The invocations of science, or "appeals to science" as the ultimate authority in persuasive discourse (Goodwin and Honeycutt 2009; Nowotny 1981; Sykes 2016), might be used differently, depending on how the students decide to talk about issues such as GMO and what points they want to make. Since there are several ways of making sense of SSIs such as GMO, what is considered an accountable way of invoking science is dependent on what needs to be addressed in situ (Mäkitalo et al. 2009; Orlander Arvola and Lundegård 2012). Students must observe and learn what is considered relevant to pay attention to in the various activities they engage when SSIs are introduced in the classroom. The ways the tasks are initiated, the resources available, and how the schoolwork will be assessed influence how the students engage with the tasks. Nielsen (2012a, 2012b), taking a pragmatic approach to understanding argumentation, suggested that a focus on scientific content in utterances needs to be studied together with the purpose of such invocations. In Nielsen's case (Nielsen 2012a, 2012b), the students were provided with written material on the subject prior to the discussion; in this study, I will study how students handle information online.

I will attend to students' discourse as locally embedded and study the discursive function of invoking science, contributing to an understanding of socioscientific reasoning as a situated and dialogical activity (Linell 2009). Such descriptive studies offer empirical examples for discussions of practices (Kelly 2008, 2011) where students reason on complex issues in science classrooms (Almqvist and Östman 2006; Furberg and Ludvigsen 2008; Nielsen 2012b; Rudsberg and Öhman 2015). By considering the local embeddedness of "invocations of science," this study aligns with such studies drawing on sociocultural, ethnographic, and pragmatist studies of learning as talk and action and contributes to an understanding of 
socioscientific reasoning as a sociocultural activity. In this study, I pay attention to the challenges students encounter when handling such complex issues in face-to-face interaction in three different classroom activities where they draw on the same message encountered online while searching for information on GMOs. ${ }^{1}$ The message was that rats got cancer from a GMO diet. ${ }^{2}$ First, students were to deliberatively talk about the controversy by considering various actors and their arguments in a small group peer discussion; second, students were to make persuasive claims and arguments in a whole-class debate-like activity; and third, students reflected in a seminar and were asked for their position in the controversy.

The following two research questions guided the investigation:

1. How do upper secondary science students draw on a recirculating message online originating from a scientific paper in conversations regarding genetically modified organisms (GMO)?

2. How are such invocations effective for students when engaging accountably in various project activities?

\section{The GMO Controversy: a Challenging Topic for Education}

GMOs are challenging to address adequately within established disciplines in education due to a range of issues such as transformation of knowledge regarding GMOs, the availability of sources, and use of increasingly sophisticated technologies. I will in the following briefly introduce the controversies around GMO and the research article authored by Séralini and colleagues that claimed that a GMO diet caused cancer in rats.

When students go online, they enter what has been described as a "constant current of images and words, a ceaseless circulation of information." The speed, stream of images, and global reach of the Internet create "a historic contextless flow of jarring juxtapositions" (DeLuca and Peeples 2002, p. 135). In the context of GMO, it has been shown how characteristics of the Internet have been utilized to create memes ${ }^{3}$ that travel freely across linguistic and cultural borders and opponents have been able to successfully refute biotechnologists' claims about the safety of GMOs (Clancy and Clancy 2016). Clancy and Clancy (2016) argue that opposition to genetically modified food can be attributed to the success of the online visual campaign against GMOs. In SSI discourses online, we may find quotations from research reports, press releases, scientists, citizens, activists, and so on. Beacco et al. (2002) show how "snatches of text" from scientists, members of the public, advocates, and others come together in media texts about SSIs, and how non-experts draw on scientific sources to create their own arguments with respect to those issues. The attraction of science as a justificatory discourse is prominent in society at large (Sykes 2016) and the recourse to science or scientifically derived principles is widespread in politics and decision-making and filters down to everyday life and practice including in schools. The political system has existed long before the Internet capitalized on "appeals to science" as a valuable resource and is using it to an increasing degree for legitimizing its decisions, incorporating scientific authority in various ways (Nowotny 1981).

\footnotetext{
${ }^{1}$ My stipulative definition of message here: quotes or formulations of the conclusion of the original research article claiming that a GMO diet caused cancer in rats.

${ }^{2}$ The research article is written by Séralini (2014) and reported on long-term toxicity in rats of a RoundUptolerant genetically modified maize (developed further in the section on GMO controversy).

${ }^{3}$ An Internet meme is commonly known as just a concept, or piece of media, that spreads, often as from person to person via the Internet.
} 
GMOs are made to produce various products more or less useful to society such as medicines or genetically modified foods. Usually, GMOs refer to crops and food, and this is also the case in the classroom studied here. An example of how to produce GMOs is moving a gene or cluster of genes coding for proteins that make fish not freeze in cold water and introduce it to a potato so the potato makes the protein resulting in cold-hardy crops. From its inception, food biotechnology has raised various questions: What are the risks of genetically modified foods? What are their benefits? How are risks and benefits distributed? Who makes decisions about them? How will genetically modified foods affect local, national, and international food systems and economies? And is it ethical to create such foods in the first place? The GMO controversy is, like all controversial issues, largely a matter of negotiating how to understand the issue itself, what should be done, and who is responsible (Billig 1996). The questions about risk can possibly be answered scientifically ${ }^{4}$ (although this issue is evidently also somewhat controversial ${ }^{5}$ ); other questions have been described to be predominantly value-based and social (Nestle 2010). Politics enters the picture since various stakeholders in the food system have different agendas and hold different values: Scientists may want to work on challenging problems that might produce health or economic gains, and, as a necessary benefit, research funding. Government regulators may want to ensure that foods are safe to eat. Citizens and food consumers can take various positions and have many different interests such as wanting to be provided with cheap, nutritious, affordable, or ecological or fair trade foods, more or less aligned with opposing or supporting production and consumption of GMOs. From a biotechnologist perspective, if genetically modified foods are safe, there is no sensible reason for regulating or opposing them (Moloney et al. 2012). In focus groups discussing GMO, it has been reported how participants use examples of the dystopian type; scenarios included invasions of killer bees, carnivorous plants, and tomatoes spreading like weeds (Marková et al. 2007) as if participants' discourse uses risk and danger as points of orientation as a kind of landmark in their argumentative discourse.

Others are concerned that the focus on science, safety, and risk obscures the social issues, particularly those having to do with the distribution of economic benefits. For instance, it has been argued (Alessandrini 2010) that it is necessary to abandon the invocation of nature and reliance on "sound science" as these continue to be counterproductive for the more interesting challenges opponents could be articulating. Alessandrini aligns with Bruno Latour and suggests that GMOs can no longer be approached as "matters of facts," but as "matters of increasing concern" (Alessandrini 2010).

The debates about food biotechnology and GMOs are complex because of the multiple perspectives involved; in addition, the science involved is also somewhat complicated. Evidently, introducing these issues in classrooms will not result in a thorough investigation of all perspectives within the research articles in every relevant field. In a school science practice, the curriculum is drawn on in order to frame the handling of SSI in a relevant manner. And since prominent school science features for the context studied here are "substantiating claims" and "evaluate different types of sources and distinguish between scientific and non-scientific

\footnotetext{
${ }^{4}$ Statement from the American Association For The Advancement Of Science (https://www.aaas. org/sites/default/files/AAAS_GM_statement.pdf): “The World Health Organization, the American Medical Association, the U.S. National Academy of Sciences, the British Royal Society, and every other respected organization that has examined the evidence has come to the same conclusion: consuming foods containing ingredients derived from GM crops is no riskier than consuming the same foods containing ingredients from crop plants modified by conventional plant improvement techniques."

${ }^{5}$ https://ensser.org/publications/ngmt-statement/
} 
claims," this will most likely be attended to in a science classroom handling an SSI such as GMO. In this article, I study closely how a widely recirculated message from the Séralini study is drawn on by students in socioscientific reasoning. The journal article was first published in Food and Chemical Toxicology in September 2012, retracted in 2013, and in 2014 an amended version of the article was republished in Environmental Sciences Europe (Séralini et al 2014) and the raw data were made public. The article presented a 2-year feeding study in rats, and reported an increase in tumors among rats fed GM corn and the herbicide RoundUp. These results, or more specifically the pictures of the rats with tumors, were spread online (Fig. 1), and the message that consumption of GMOs has caused cancer in rats is reported by many different actors in the controversy online.

Students and teachers in Swedish schools typically do not have access to scientific journals and will consequently encounter paywalls if they click on links to scientific articles. This limits the possibilities for critical disciplinary engagement when they encounter scientific claims online such as looking up articles on GMO safety, and as a consequence they are left to deal usually only with what is freely provided online.

\section{A Dialogical Perspective on Students' Invocations of Science}

Our understanding of utterances requires a reference to the larger activity of which they are part (Levinson 1979). Levinson's various examples on institutionally embedded interaction, including questions and answers in courts and classrooms, demonstrate how our conclusions about what has been accomplished through talk "rest on our knowledge of the kind of activity the talk occurs within" (Levinson 1979; p. 382). In this article, I draw on dialogic theories of communication and the analytic concept communicative activity types (CATs) (Linell 2010; Marková et al. 2007) to understand student conversations regarding SSIs. Combining

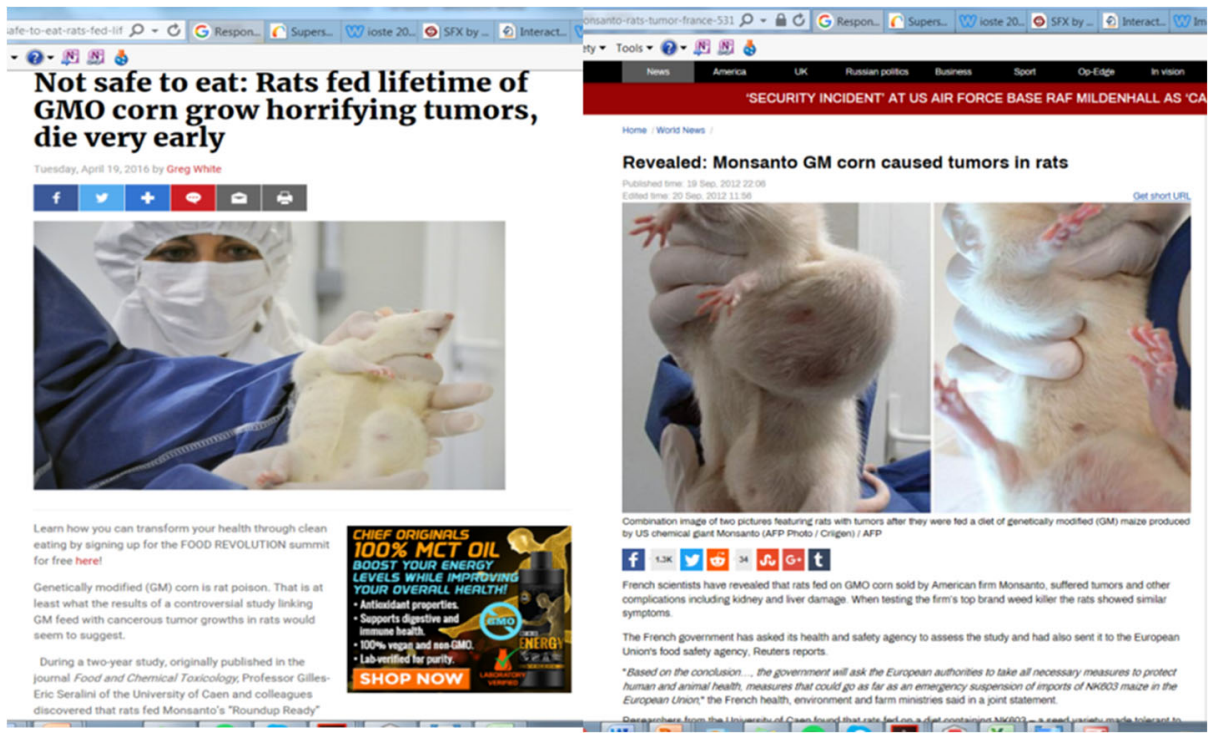

Fig. 1 Articles (left, www.gmo.news; right, www.rt.com) reporting how rats fed GMO grow tumors, both citing Séralini's research article 
microlevel analyses of video data and use of ethnographic data that constitute the basis for providing "thick descriptions" of the observed activity are necessary for an understanding of social interactions (Jordan and Henderson 1995). The students' action and discourse are accordingly understood as contextualized (Linell 1998b). Students are accountable for what they say and do in interaction with each other and need to contribute with comprehensible and recognizable contributions to a conversation or a discussion; an utterance must be designed to fit certain particular conditions of where it is to be performed (Buttny 1993; Mäkitalo 2006). When SSIs are introduced in the classroom, students must observe and learn what is considered relevant to pay attention to in the various activities they engage. The ways the tasks are initiated, the resources available, and how the schoolwork will be assessed influence how the students engage with the tasks ( $\AA$ berg et al. 2010).

When I study the students' dialogue and how the message that GMOs have caused cancer in rats is recirculated, it is important to emphasize that this does not presuppose any set of fixed and ready-made ideas that just move around. Rather, the ideas are "continuously or at least potentially negotiated, modified and transformed as they circulate in dialogue" (Marková et al. 2007, p. 133). The communicative situations studied here do not occur in isolation; rather, they are connected in various ways, across space and time through artifacts such as written texts and photos online. This means that discursive content will travel across situations. This phenomenon involves recontextualization, "the dynamic transfer-and-transformation of something from one discourse/text-in-context to another" (Linell 1998b, p. 144). This means that there is no pure transfer of a fixed meaning; rather, recontextualization involves transformations of meanings. In the setting studied here, recontextualization can for instance include that a part of a text such as a piece of evidence or conclusion from a scientific article in a journal is fitted into another context such as an activist group's Web page.

The analytic concept that will be utilized for understanding the students' reasoning is CAT. CATs provide a link between the situated microprocesses and the societal macrostructure of discourses, between focusing on the detailed specifics in a dialogic exchange and focusing on the communication as a particular type of social situation (Linell 2010). In the following, CAT will be developed for the purposes of understanding analytical procedure and findings in this paper. Communicative activities are carried out for particular purposes accomplished by people together in situated encounters, and the activity type defines the situation for the actors engaging in it, telling them what is "going on" in the situation (Linell 1998a). At school, students participate in different types of activities such as science labs, lectures, students' presentation of group work for the class, and debates. In science education in schools, these situations are linked to discourses such as scientific argumentation and arguing controversial issues in a debate. The activities are also framed by specific expectations and purposes that the participants are oriented to, such as whether the activity is formally assessed. The CAT analysis can be performed on various empirical overlapping and interdependent dimensions (Linell 2010).

In this article, I will attend to a limited number of empirical dimensions particularly relevant for the analysis of how students draw on claims recirculating online in school science such as the purpose of the activity and how participants adopt activity roles (see "Data Production and Analytical Procedure"). In the analysis, I will show examples of how students use roughly the same message, and design it to fit the particular circumstances of different activities commonly arranged for educational purposes in school. In the following section, I will briefly describe the context of the study and the activities analyzed. 


\section{Controversy Mapping in a Science Classroom: the Empirical Setting}

Understanding SSIs calls for the creation of activities in classrooms that enable young people to reflect critically and carefully by examining the actors and their claims, interests, and affiliations (Walsh and Tsurusaki 2018; Zeidler 2014). Working with SSI calls for cross-disciplinary projects (Levinson and Turner 2001), since the relevant science regarding these issues is complex, multidisciplinary, emerging, and contested. In addition, they encompass multiple ethical, social, economic, legal, and political dimensions. Coming from the subject areas of English, physics, Swedish, and biology, the four teachers involved in this study were used to working together in cross-disciplinary projects on sustainable development that matched the interests of the research group. The students had been involved in projects on sustainable development and used the Internet for searching for information, but teachers were concerned how the students searched and evaluated information online so they welcomed an approach that provided tools for exploring and visualizing online information. The students had not previously worked with SSIs in the present school context.

The data used in this article was collected in a grade 11 science class (ages 17; in the class of 25 students, 12 were girls and 13 were boys) where students worked with controversy mapping (Venturini 2010b) as part of a 3-week-long school project concerned with science-in-society. The aim of the school project, as formulated by the teachers, is to examine a controversy through a method called controversy mapping, not by finding one answer but by examining different perspectives and actors within the area. Through this process, the students were to develop an ability of assessing different types of information sources, be able to distinguish between scientific and non-scientific claims, understand how science and the development of society both affect and are affected by each other, recognize the role of science in questions concerning how sustainable development issues are mutually influenced and influence each other, and recognize the role of science in sustainable development issues. These aims were coupled to goals described in the curriculum.

Prior to the start of the instructional unit, students were informed about the research project and most of them agreed to be video recorded through all the lessons. The teachers formed the five groups, out of which one consisted of students who did not want to be video recorded. Three of the groups worked with GMO and two groups worked with fracking. The students' project was initiated by a group of researchers in education and science studies ${ }^{6}$ and collaboratively developed by teachers from an upper secondary school along with a pedagogical developer focused on the integration of information technologies (IT). The pedagogical developer was employed at the university developing and supporting use of digital tools in education projects.

One teacher acted as the link between the school and the research team. This included, for example, finding appropriate controversies to work with since certain controversies were deemed inappropriate for digital mapping. Some controversies were judged not to be active enough online to produce usable maps. An example of such controversy that one teacher was interested in exploring was fishing quotas. Other controversial issues such as marijuana use

\footnotetext{
${ }^{6}$ The educational researchers were concerned with learning in digital environments and science education and STS researcher was interested in new forms of public engagement and involvement in science and technology. These researchers had identified controversy mapping as a fruitful focus for collaboration and contacts were made with the Médialab in Paris to discuss how teaching methods might be successfully adapted to a school context. The four educational researchers (two professors, a lecturer, and a PhD student) and the STS researcher all participated in planning the activities. The STS researcher introduced the concept of controversies to the students, and the lecturer and the $\mathrm{PhD}$ student were responsible for producing the classroom discourse data with assistance from technicians.
} 
were deemed by teachers to be unsuitable for the particular school setting. Following this selection process, it was decided that the students would work in groups of four to six on either GMO or hydraulic fracturing (fracking).

First, the students were introduced to the project by the teachers who also provided the students with written information on the goals, grading criteria, and plan for the different activities (Appendix 2). Then, the notion of socioscientific controversies was described by a researcher and the digital mapping tools were introduced and their use supported by the pedagogical developer. The digital mapping tools provide means to explore, manipulate, and visualize networks of online data and to work out what is relevant and useful when exploring a controversial issue from a corpus of online data (Jacomy et al. 2014). These maps are used as both instruments to explore the controversy and tools to present it to others (Venturini 2010a; Solli et al. 2018).

Following this introduction, students started collecting online trace data generated from visiting Web pages on their assigned controversial issue. Throughout the project, the students worked in groups, everyone having access to their own computer, and worked alternately individually and together. They searched for information online through Google, using a harvesting tool to collect all Web pages visited and the data corpus of Web pages and the links between them were imported to Gephi ${ }^{7}$ a network visualization program. The data were presented in visual form, presenting how websites of the different actors were connected through links. This visualization was called a controversy map. When the students had generated the map, they engaged in various forms of school project activities involving communication with others:

- Peer discussion: A group of 11th grade students were asked to account for the controversy over GMO from the maps they had recently generated for 12th grade students (ages 18). The older students had used ordinary search engines to orientate themselves and prepare questions.

- Debate: Ten 11th grade students on the panel enacted a specific actor in the controversy led by a science teacher who moderated the discussion. In the audience, 12th grade students acted as journalists.

- Seminar: The seminar groups consisted of 11th grade students, mixed with regard to controversial issues worked on, GMO and fracking. The group was led by the Swedish teacher who asked reflective questions. On this occasion, the students were asked to give their own opinions on the issue and encouraged to substantiate their claims.

During project class time, at least one, sometimes two, teachers were present in the classroom. Often, they initiated the activity in full class and were available for questions, but also periodically engaged with group discussions and work in progress.

\section{Data Production and Analytical Procedure}

All students' classroom activities were documented using tripod-mounted video cameras positioned to record all the students who participated with microphones placed on the tables they worked at. The interest in this study was the students' invocation of science in reasoning

\footnotetext{
${ }^{7}$ Gephi is open source and free: https://gephi.org/
} 
in various activities. For the purpose of this study, a dataset consisting of verbatim transcripts of video recordings of the three classroom activities, peer discussion, debate, and seminar, was used. The transcripts have been translated from Swedish into English and a subset of Jeffersonian (Jefferson 1984) transcription conventions was used (Appendix 1). After reading through these transcriptions a number of times and coding terms and sections related to mentioning of scientific studies, the particular message that GMO had been shown to cause cancer in rats was frequently recirculating across the material and was chosen for further analysis. Following the tradition of interaction analysis, the analytical procedure was conducted iteratively by viewing the video recordings and the transcripts to distinguish patterns in the participants' activities through their interaction with each other. Observations of students' interactions were made by the author and brought to joint video seminars for analytical discussions with the rest of the research group. Combined microlevel analyses of video data and use of ethnographic data that constitute the basis for providing "thick descriptions" of the observed activity were according to interaction analysis deemed necessary for understanding the interactions (Jordan and Henderson 1995). Ethnographic data made it possible to understand how the microlevel activities are part of locally situated contexts and institutional practices (Linell 1998b, 2009; Mercer 2004) .

One important consideration for research of the kind conducted in this study is whether or not observations are based on reliable data. Recording educational situations in situ raises the issue of how cameras and researchers might affect participant conduct and interaction and it has been suggested that this is an empirical question (Heath et al. 2010). In the data material, there are a few occasions where the participants clearly noticed the camera and the recording procedure. One general observation was that the tasks at hand generally took participants' attention away from the recording process. The observation in this project was that students spent very little time off task, which the presence of researchers and cameras probably contributed to. Capturing interaction in this manner not only offers documentation of the physical place where students and teachers work, but also makes it possible to revisit the activities and observe them in detail.

I was interested in the work the students performed on the recontextualization of this particular message in the different classroom activities in the school projects. Therefore, the selection of excerpt examples was guided by orienting to the notion communicative activity types (CATs) (Linell 2010). In order to illustrate the forms and functions of the instances of students drawing on the message from the Séralini study and how it is transformed as it is moved across the CATs, classroom discourse examples were chosen to illustrate the ways in which students recontextualized the message: when they presented an overview of arguments and discussed the rhetorical use of science on the Web; when they argued for an actors' position in a debate; when qualifying their own stance in a seminar. To understand the students' argumentation in interaction, the analysis establishes how the participants define the communicative situation. This is achieved by attending to external and internal framings (Marková et al. 2007). The external framing pertains mostly to three points: purposes and tasks, setting and time, and group composition:

I. Purposes and tasks: the pre-interactional framing concerns the purposes stated beforehand, apprehensions regarding assessment or not, teachers' instructions, and other ways of organizing the setting such as providing tasks to students to prepare for the activity and also how the teachers present the task when initiating the activity in the classroom. How the tasks are actually carried out in the activity is of central importance. 
II. Setting and time: considering the impact on the conversation practices by the physical organization and time constraints.

III. The composition of the group involved including social roles: are the teachers involved in the discourse?, etc.

The remaining points are more related to "internal framing"; the actual staging of the activities:

IV. The activity roles enacted by the participants such as inquirers, rapporteurs, opponents, supporters, etc.

V. Which dominating discourse type is actually used: what external framings actualize specific discourse types such as narration, argumentation, instruction, and small talk?

\section{Findings}

I will in the following present an analysis focused on the detailed specifics in the students' dialogic exchanges and on the communication as a particular type of social situation. Reasoning is thereby understood as sociocultural activity, and the meaning and function of invocations of science were analyzed when students discussed GMOs in various classroom activities: (1) a deliberative peer discussion, (2) a staged debate where various actors were enacted, and (3) a reflective seminar. In these contexts, the students were drawing on previous experiences and dialogues with peers and online texts, and in the particular situation they had to choose a way of using the discursive resources available in ways that corresponded with the task given by the teacher and the contextual premises in the school setting such as orientation to the curriculum and grading criteria. Looking across the three classroom activities as students talked about GMOs, they repeatedly referred to the message from a scientific study by Séralini. Interestingly, the students had not engaged directly with the research article, but relied on research findings as they were presented via various actors' websites. The message of the paper with photos of cancerous rats reportedly caused by a GMO diet was circulating online (Clancy and Clancy 2016), and turned out to be recirculating widely on publicly available online websites in opposition to results of the hundreds of other recent scientific papers in the GMO field mostly available in scientific journals only (Sanchez and Parrot 2017).

The persuasive power of "appeals to science" as a discursive resource is illustrated when students enlist scientific objectivity and rigor to underpin the credibility of socioscientific arguments both when presenting an actor's stance in a debate and when qualifying a reflective position in the controversy. When students were engaged in deliberative discussion, students act as rapporteurs of others' claims online, critically discussing and reflecting on how actors in a Web context use appeals to science rhetorically.

In the following, I will present how students made different kinds of invocations of science relevant by attending to the external and internal framings for each activity type. The aspects of framing attended to were purposes and tasks, setting and time, and the composition of the group and the actual staging of the activities, discourse type, and activity roles.

\section{Deliberation}

In this activity, the rapporteurs were expected to provide a description of the controversy which implied a "non-biased," "objective," or "neutral" account as reflected in the questions to be 
answered in a written preparatory task to be submitted just prior to this occasion: While the activity was not called anything in particular, it resembled smaller group or team-based oral work; smaller scale settings for deliberation typically allow student participation not possible in larger groups. This activity was reminiscent of deliberation meetings where the public are provided opportunities to talk with others, some as rapporteurs of a specific research field for instance, and others as inquirers focused on considering diverse points of view and discover key tensions and values, often arranged in order for the meeting to reach a consensus. In this activity, in accordance with the teachers' framing, the careful consideration of the issue aimed at coming to a common understanding of what constituted the controversy.

The students were left to talk for as long as they needed to, within the time frame of $90 \mathrm{~min}$. The teachers were not actively interacting for the larger part of the activity; rather, they introduced the activity in full in class and also concluded it after about $40 \mathrm{~min}$ with suggestions for how to follow up this conversation. In this activity, students were gathered around the controversy map, printed and placed in the middle of the table (Fig. 2).

The students in grade 11, in this activity acting as rapporteurs, were given pseudonyms starting with R: Roland, Ruth, Rasmus. They brought their computers containing the digital map, occasionally oriented towards each other. Students from grade 12 mostly asked the questions, and acted as inquirers, with pseudonyms starting with I: Imre, Isak, Ivar. In this activity, the students oriented to the oral instructions given to them by their teacher which were to account for controversy, in this case GMO, from maps they had recently generated. They were to report to the inquirers who had used ordinary search engines to orientate themselves to prepare questions. The printed controversy map functioned as a mediating artifact (Wertsch 2007) supporting the students' discussion by visually stabilizing stakeholders and positions, making them publicly and jointly available for use. Since the map was a product of their earlier joint work, the rapporteurs could rely on it as a memory device while acting as

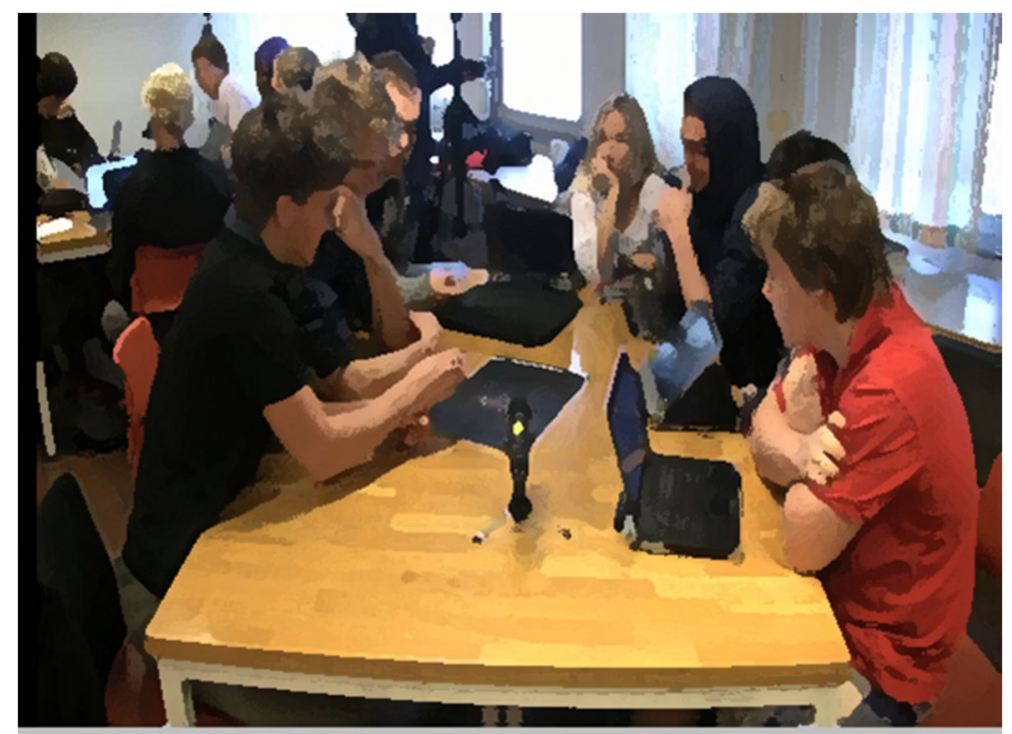

Fig. 2 A peer discussion: students seated with a printed controversy map on the table. Rapporteurs to the right and inquirers to the left 
rapporteurs, engaged in the controversy of fracking. As rapporteurs, they found themselves in a position where they were held accountable, having to explain and answer to the inquirers' questions. As example 1 will illustrate, the students first invoked the message from the scientific article to merely report and provide a convincing account, whereas in example 2 the students evaluate knowledge claims online: the message became an example of an extreme case used by opponents and popular press online to scare consumers. Deliberation and reporting of others' claims typically allow for individuals to move between arguments and positions as will be seen in the following.

\section{Example 1 Trustworthy Reporting of Others' Claims}

When the rapporteurs present the controversy to the inquirers, they were faced with the task of providing a convincing account of what constitutes the controversy they have encountered online and being attentive to the sorts of comeback and questions the inquirers may have of the particular factual formulation. The challenge was thus not to convince the others to take on the arguments themselves; rather, here, it was about being a trustworthy rapporteur with a critical approach. In the first example, students did not express their commitment to the message recirculating online; rather, they report others' prototypical arguments. The excerpt below was following a discussion on how they were going to use the map in the continued work: that they were to analyze it and that it was challenging since not many actors in favor of GMO were identified. That initiated the topic of what kinds of arguments were most common "on the opponents' side":

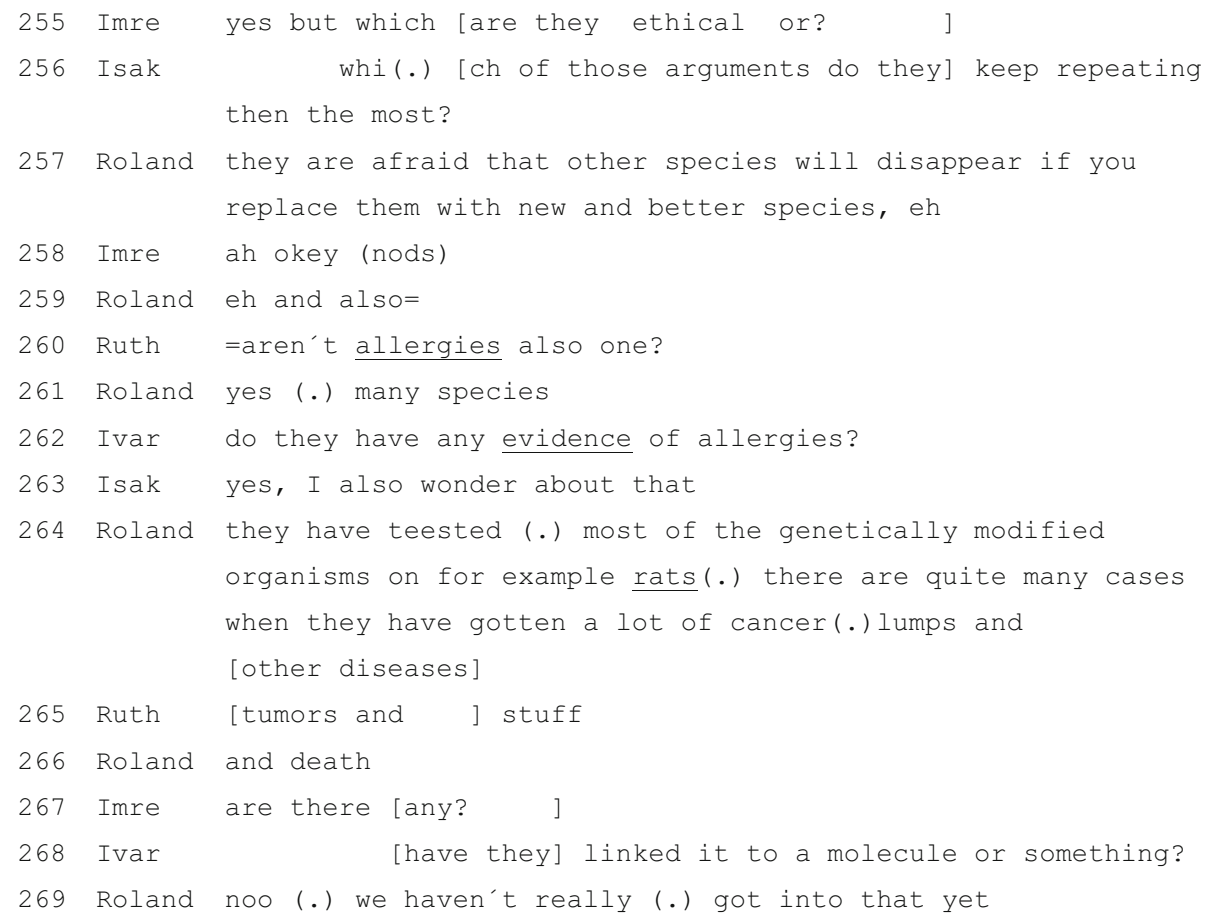


The inquirers' questions were inviting accounts of what kind of arguments were mostly repeated by the opponents (256), and arguments were exemplified as disappearance of other species (257) and allergies (260). When the rapporteurs mentioned allergies (260), the inquirers followed up requesting the rapporteurs to report if there is any warrant for that claim, i.e., if the opponents have provided evidence regarding allergies $(262,263)$. The rapporteurs provided an elaborated account exemplified with the results of a scientific experiment which alludes to the evidence part of the question that was emphasized, "they have tested most of the genetically modified organisms" (264) that caused [lots of cancer tumors] $(264,265)$. The study referred to and already recontextualized by actors online, the contested Séralini study, was here invocated to provide the group with only one example of the kind of evidence that exists out of many studies both in numbers ("quite many cases" (264)) and type of animal ("for example rats"). To present the study in this way allowed the inference that the evidence was general and widespread, which contributed to its fact constructional role, and perhaps not having to provide more science "as evidence."

During this presentation, the rapporteurs had one central task, which was to be able to tell a trustworthy account of the map and the controversy online. They were entitled to provide a somewhat authoritative description of the arguments encountered since they were positioned by the teachers as the ones who were to explain. The rapporteurs, having worked extensively with pages online, provided convincing accounts by referring to an experiment "they have tested" (264) including details of the kind of experiment conducted involving rats and cancer referring to specific knowledge which is hard for outsiders such as students not involved in the project to apply. This means that it was ideally suited to be used to warrant the rapporteurs' claim. However, requests for more detail and possible mechanisms underlying the development of cancer by asking whether a molecule had been linked to the problems associated with GMO were posed $(267,268)$; this can be seen as an inquiry into how convincing this piece of argument was and possibly checking whether alternative explanations could be ruled out. The reply indicated that this relevant piece of information is missing (269), possibly showing students' awareness that this may be an ongoing issue of establishing evidence. Since the students were accountable to report correctly, and signaling uncertainty when it needs to be addressed, they suggest that it is something that should be done in order to assess these types of arguments further and mark out that they are in a process of studying the issue and might be in the process of reading more in depth. In other words, whether a molecule has been connected to cancer is relevant in science and in this school science context. The specificity of this question may put the rapporteurs' entitlement to speak convincingly on the topic in doubt. Still, receiving such a relevant question in this low-stakes situation encouraged the rapporteurs who soon were to engage in a more formal public forum like debate to be prepared for such questions, and maybe even look up whether such molecules have been identified.

While in the first example inquirers asked for the most common arguments and the rapporteurs reported others' claims, the next example shows how the inquirers ask which "strong arguments" exist-which invited an evaluative perspective. In the next example, students had just moved on from talking about "strong fact-based arguments" that exist to other "strong" arguments: 


\section{Example 2 Critical Reviewing of Others' Claims}

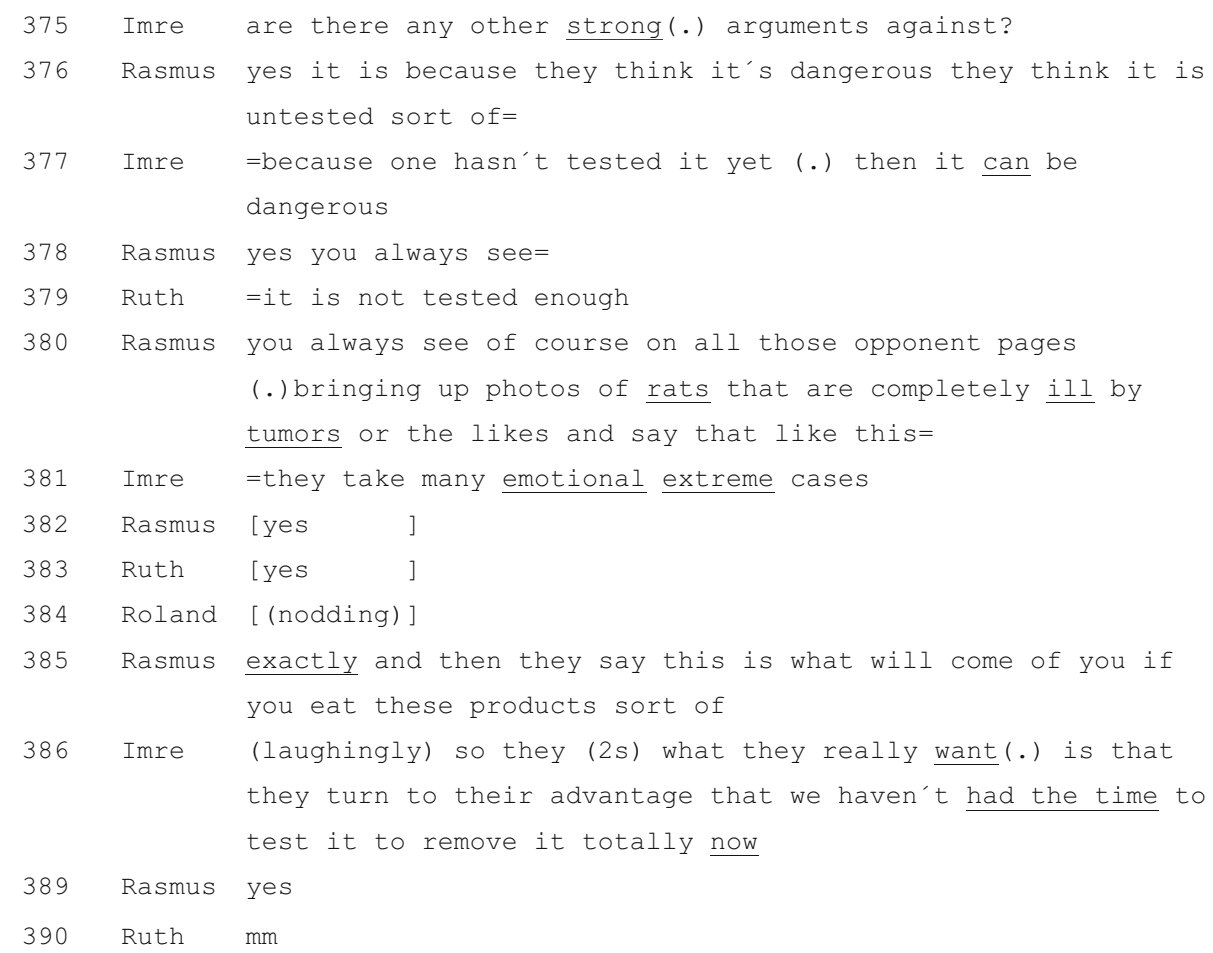

When the rapporteurs were answering the question whether there were any "strong arguments against" (375), they reported how the opponents claim it is dangerous and untested (376) which is also repeated by Imre in (377), and in the next turn Rasmus provided the ground to support the rapporteurs' claim that opponents say that GMOs are dangerous and untested by referring to opponents' use of photos of ill rats with tumors (380). Rasmus offered an evaluative perspective on the evidence, quoted by talking about the usage of it by the opponents as somewhat exaggeratedly used to threat citizens ("this is what will become of you") (386); together, they expressed agreement that the photos can be seen as "emotional extreme cases" (381-385) and distinguished opponents' popular press type of arguments from scientific forms of arguments. The experiment on rats was established as something others use online as extreme cases and also possibly distancing themselves from the use of this article in their own argumentation.

In providing these evaluations of the evidence and the opponents, the meaning of the message was altered: previously used to present prototypical types of arguments, now an example of extreme cases used to evoke emotions such as fear or used by 
online media to create newsworthiness. The status of the information changed from being a part of a group of scientific results where several types of GMO have been tested on various animals, to being something of an emotional extreme case to scare potential consumers with. In the first example, the students invoked science in order to be able to provide the inquirers with the relevant information on the typical arguments used by opponents in an accountable way; here, they refer to the photos of cancerous rats to warrant the claim that opponents claim it is dangerous and untested and showing that they understand the rhetorical context of the Web. The students were not merely animators reporting claims of others, and as such reporting facts including the facts of others' claims, they were also critical reviewers of the information they have encountered. The students used quotes uttered by others that were often ascribed to constructed collectivities such as scientists or opponents as if these communities could express their views with one voice. In this CAT, it serves the purpose of organizing the controversy in order to make it comprehensible to others.

In the two following communicative situations, both formally assessed, the science effectively provided students with evidence to substantiate claims. In the situations, students argued as "opponents" in the staged debate-like activity, and in a seminar to qualify their own position.

\section{Debate}

Before this activity, the teachers had assigned each student to a side in the controversy; the students had identified the various actors and prepared to use arguments that these actors typically believed to deliver when participating in debates. For preparation, the teachers had provided the students with questions the "journalists" may ask. ${ }^{8}$ To this event, the students brought "cue cards" as memory aids in preparation for anticipated questions during the discussion. This activity was towards the end of the school project and a high-stakes activity since the students were expected to present to the teachers, through bringing forward their actors' arguments, what the examination of different actors and their arguments had resulted in. The activity took place in the schools' lecture hall where the students were placed in one side of the room; those assigned a role as opponents to the right and those assigned the role as supporters on the opposite side, to the left (Fig. 3). The students were facing the audience consisting of the students from 12th grade acting as "journalists" and peers who had worked on another controversy. A science teacher was moderating the debate and a Swedish teacher was in the audience taking notes for the formal assessment.

In the school project description, this incident was referred to as a "press conference" since "journalists" were there to ask different "actors" questions before an imagined GMO research facility might be established in the local community. However, when the activity played out, it took the discursive form of a debate: with two sides, a proposition side and an opposition side laying out their most important arguments during speeches (seen in example 3 below).

\footnotetext{
${ }^{8}$ How would you describe the controversy? What is your attitude towards it? What arguments do you have for your case? What kind of opposing argument do you usually encounter?
} 


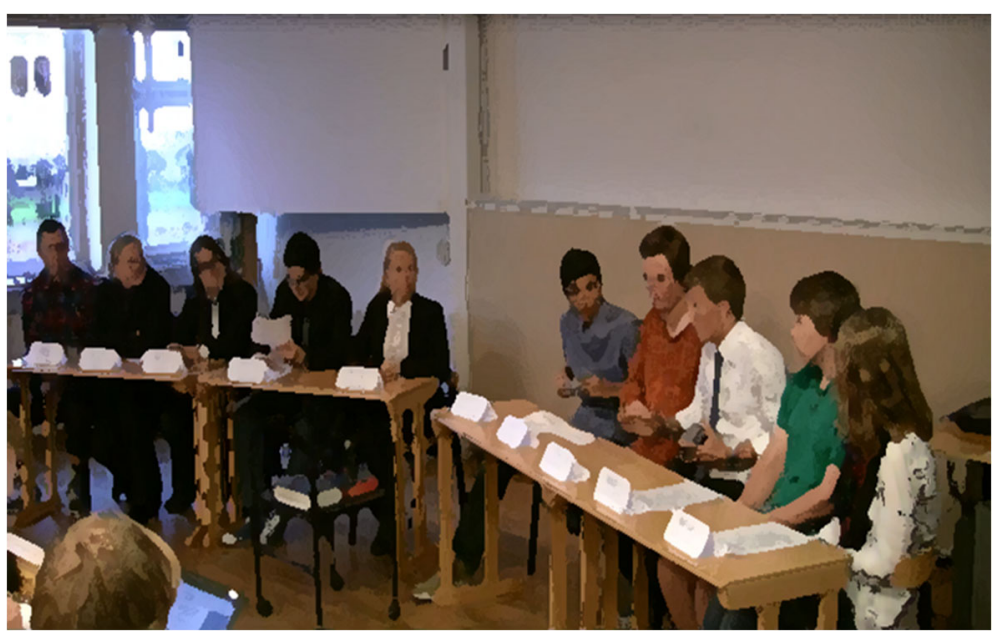

Fig. 3 Debate. Students 1 to 10 (right to left), represented different actors in the GMO controversy. The opponents: 1 and 2, organic consumers; 3, Greenpeace; 4 and 5, Non-GMO Project. The supporters: 6 and 7 , Monsanto; 8 and 9, NCBI (National Center for Biotechnology Information); 10, ISAAA (International Service for the Acquisition of Agri-biotech Applications). "Journalist": 12th grade student asked questions: sitting with backs to the camera, one is visible in the lower left corner

An activity is recognized as a debate when contention in an argument is involved, often on controversial issues. In this rather formal discussion (compared with smaller, more deliberative discussions) before a full-class public assembly, the students took on the task of making persuasive and logical arguments in a manner tailored to be accessible to the varied audience with peers and assessing teachers. During this activity, the students were involved in a structured consideration of some issue from two or more points of view and discursively contribute as opponents or supporters of the issue at stake. As in other debates, the students were arguing one side throughout the activity. The physical arrangements emphasized that this was a high-stakes event where "being on stage" and performing good arguments were salient components. Seating the opponents on one side and supporters on the other in front of an audience consisting of other classmates and older students as journalists, all had an impact on the discussion. During the activity, the different sides were sometimes addressed to respond to questions, diminishing the types of actors. As a discursive practice, the activity is characterized by opposing stances; each participant criticizes the other's ideas by providing adequate arguments and justifications that support one's own ideas and weaken the validity of the other person's ideas, with the goal to convincingly deliver one's actor's arguments and solutions (Asterhan and Schwarz 2016).

\section{Example 3 Arguing for a Position}

The excerpt below was from the beginning of the activity following a round where the actors introduced themselves and the moderator opens up for questions from the journalists where they ask the actors about their views on the GMO field: 
51 Teacher

52 Journalist

53 Teacher

54 ISAAA

55 Teacher

56 NCBI

57 Monsanto

58 Teacher

59 NonGMOproject

60 Teacher

61 Greenpeace

62 Organic consumers

63 Teacher

64 Journalist do you want to address someone in particular?

mhm no (.) I think I want to hear what everyone has to say yes okay (.) let us simply start from the other side (lpoints to the left of the panel, the side of the opponents))

eh yes GMO we eh (1s) we think that GMO is very good for a sustainable development of society eh and we think that gene plants and biotechnological farming can become a partial solution to global poverty and environmental degradation (3s)

((points to the next student in line))

Eh yes we think that since the yields in the world have decreased significantly thanks to being affected by parasites and crop-eating insects (.) eh so insectresistant crops can make so that the world gets more food and well these insect-resistant crops can be produced through gene technology ((occasionally reading/looking at her cue card))

eh we also think that GMO is good because of higher yields and lower costs for the farmers and reduced usage of herbicides and pesticides eh so yes (2s)

((points to the next student in line))

we consider that the risks are not mapped out (.) the risks are tested in the short run but not on the long run eh there has been too little research on GMO to be able to foresee the consequences, but one study has been conducted on rats and in that study rats are fed gene modified corn and the result became that $50 \%$ of the eh eh the male rats died prematurely and $70 \%$ of the female eh died prematurely also ((turning the page of the cuecard)) and this is not normal and they died due to tumor development yes (nods)

Greenpeace ((looks at next student in line)) eh we do not think that genetically modified food is the solution to any (charity?) problem we do not think it is the solution to world hunger (.) We do not think it is the solution to our environmental problems (.) we believe in concrete solutions that do not involve experiments with mother nature

yes, eh we in organic consumers do not think it's tested enough, it's still uncertain what effects genetic modification can have on humans and on nature in general(.) and we prefer to eat organic crops and yes we think so was that an answer to (.)? ((addressed to journalist)) absolutely 
In this round, the students were invited to make a case for their position in the controversy. The students have prepared to answer this request; they all occasionally glance at their cue card, so it seems reasonable to assume that their claim is thought through and based on the actors' positions. Following a series of claims from supporters of GMO, a student that enacted a representative from Non-GMO Project was positioning himself against the supporters that have spoken prior to him. He claimed that the risks were not sufficiently identified and that more research needed to be done (59), which was also claimed by organic consumers (62). The Greenpeace representative was explicitly making counterclaims to the previous speakers' by emphasizing what they claim as opposed to the supporters "we do not think it is the solution to world hunger (.) we do not think it is the solution to our environmental problems," thereby discursively organizing the activity as a debate. Here, the message of tumorous rats that has circulated online was first introduced in this activity to back up the claim that GMOs are risky and that more research is needed to foresee the consequences. These claims enabled the student acting as an opponent to invoke seemingly credible and objective facts from what he presented to be one of the few research articles in this area. He reported that rats developed cancer prematurely because of GM food: "the result was that $50 \%$ of the male rats died prematurely and $70 \%$ of the females died prematurely as well this is not normal and they died because of the development of tumors." Quantification is often thought of as an especially precise and clear-cut form of description which is contrasted with value judgements and vague qualitative assessments. Indicating quantity has been shown to be powerful and convincing (Potter 1996). The Non-GMO Project representative used another general feature of making a convincing fact description (Potter 1996), including specificity of the results of an experiment by providing the percentages of the rats who died, divided into males and females. Acting as a representative of an interest group, he balanced the need to create public concern ("we regard that the risks are not mapped out") with the need to retain scientific credibility by being very well informed down to the details in the scientific studies regarding this (Solin 2004).

In debate-like situations, it has previously been shown both in scientific and everyday settings that people will provide increasingly technical support for positions, making a version seem credible and objective (Latour 1987). The student used what has been termed an externalizing device which is a characteristic feature of the empiricist repertoire by attributing agency to experimental data ("the results show"). This form of empiricist discourse can be understood as an extension of this process. The support for the Non-GMO Project stance was built up by constructing the facts as having their own agency. Such constructions obscured the work of interpretation that was done by the student who described the situation: "the results became": first, not being constructed as facts and, second, their significance was not being generated by their producer. It was provided by the facts themselves. The empiricist repertoire can be considered as a set of resources that may be drawn on when externalizing facts by divesting agency from fact constructors and investing it in facts.

\section{Seminar}

This activity was used for formal evaluation: the grading criteria that were communicated to be relevant to this seminar were in the science subjects physics and 
biology, such as the ability to use knowledge in science to communicate and to evaluate and use information. The seminar was the closing activity in the school project; the participants were informed that on this occasion they were to reflect on the knowledge relevant to the issue, the whole project process, production of the maps, and the conclusions they have been able to draw. In addition, the teacher provided the students with the questions they should be prepared to answer the day prior to the seminar. The responses to the teachers' questions that students came up with were based on the complex interaction of many perspectives they had been in contact with throughout this project. To position themselves in this context implies an end to deliberation. The chosen alternative had to be defended against criticism, not in interaction but as a delayed response when evaluated. The students had to choose a way of using the resources available in ways that corresponded with the contextual "rules" that apply here.

The activity is similar to other activities we recognize as seminar-a form used in educational institutions, bringing together small groups for focusing on some particular subject where the content is reflected on and questions can be raised and everyone present is requested to participate. This is often accomplished through an ongoing dialog with a seminar leader: in schools typically the teacher. In this activity, the students from both fracking and GMO groups are placed around the table, and the Swedish teacher is moderating the seminar (Fig. 4).

The teacher took on the role as moderator and the students provided reflective answers and actively contributed to the conversation in an accountable manner. This seminar lasted for about $30 \mathrm{~min}$ and the teacher was allocating speaker turns, organizing the discussion by posing the prepared questions. All students answered the questions in turns and concisely. The teacher mainly provided minimal responses such as "mm" indicating that she was listening and encouraged further talk, but did not respond to or evaluate the students' contributions in any elaborate way unless the students asked for clarification.

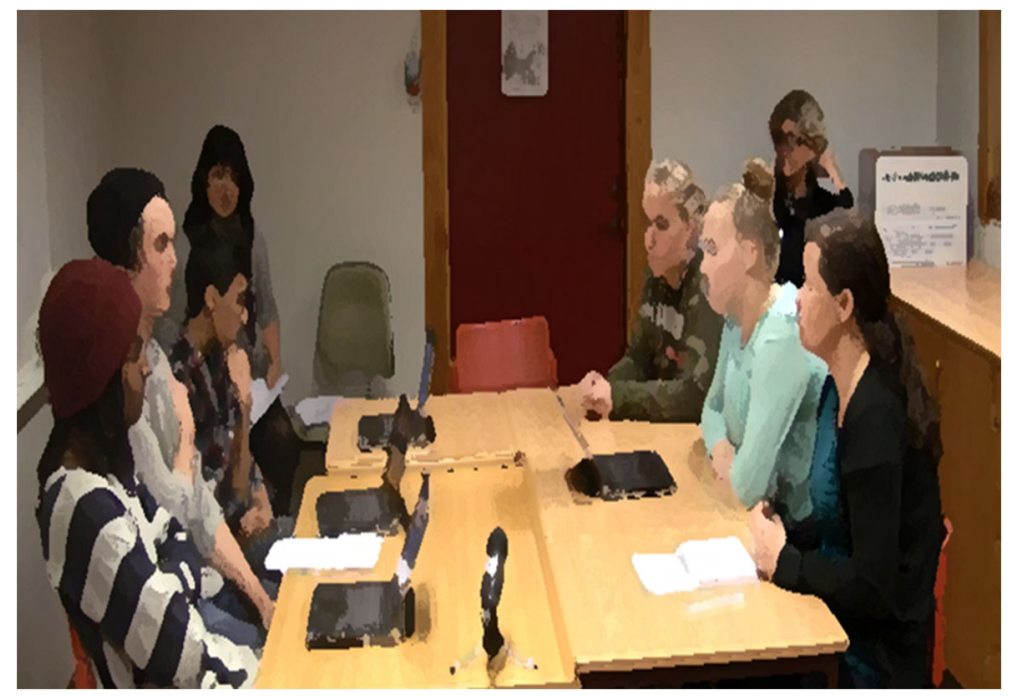

Fig. 4 The reflective seminar: students from GMO and fracking groups and the teacher 


\section{Example 4 Qualifying a Position}

In the excerpt below, toward the end of the seminar, the students were asked how they position themselves in the issue they investigated. The students' mixing or blurring of different voices and interests could be observed in the classroom SSI discourse through the communicative activities. Students had many opportunities to select suitable science (i.e., suitable for particular purposes), edit these parts in new ways and combinations, and subdue or silence voices that had been heard earlier, or could have been heard at various stages. Not everything said can be carried along and included in the seminar. But the message that consumption of GMOs has led to tumors in rats was drawn on also at this occasion.

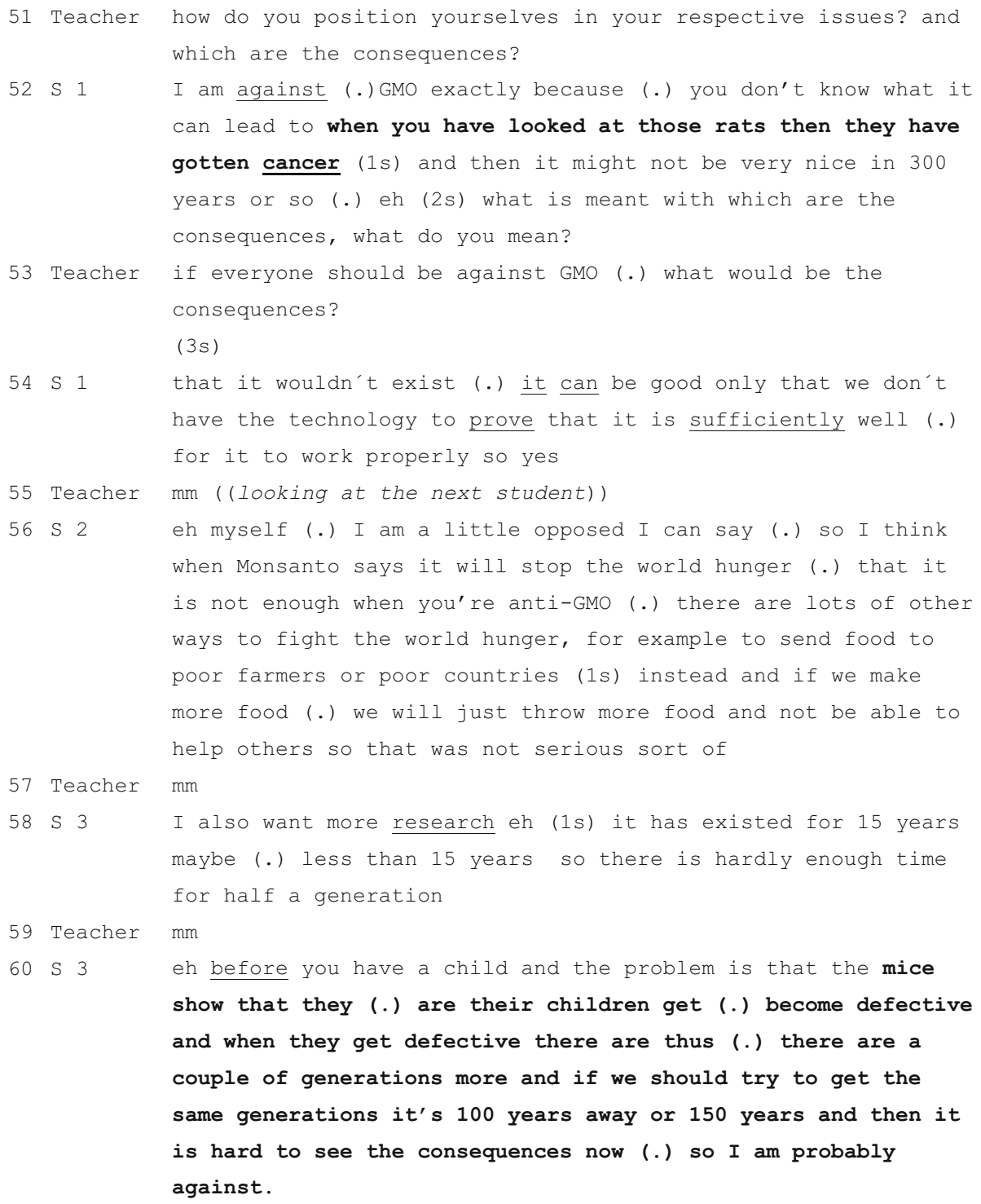


Here, the students invoked the message that rats gets cancer (151 and 159), and the appeals to science is used to back up students' communicated stance regarding GMO: that they are against $\operatorname{GMO}(151,155,157)$ and that more research is needed $(153$, 157). On this occasion, students were required to provide justification for their own position. In the seminar, students were required to manage their own accountability in the performative context of school and managed this through citing evidence. It became relevant to cite scientific sources and handle a seemingly indisputable fact ( "those rats they have gotten cancer" (151); "the mice show that they become [defective]" (159)) as a cautionary tale and call for more science and more research. By appealing to science that helps support their point, they were provided with credibility and strengthening of their position in this activity type where the aim is to display the ability to provide reflective positions and explaining them to the teacher. The students showed that they were aware of the value of providing support for their positions and claims which is a cross-disciplinary feature of scholarly practice (Engle and Conant 2002): strong scientific evidence and appeals to it still constitute by far the most powerful argument (Nowotny 1981; Sykes 2016).

The student (S 3) was displaying responsibility by talking about consequences of our choices for the future. She maximized uncertainty by talking about the far future when justifying the claim that more research was needed: "it is 100 to 150 years away, and very hard to foresee the consequences so I am against" (159). Referring to consequences $(150,152$, 159) could be seen as the participants' orientation toward the grading criterion that mentions the ability to foresee consequences of stances in particular. And justifying their position by reference to common good versus own preference also shows orientation toward a school science discourse that is performed here.

\section{Discussion}

\section{Studying Students' Reasoning as Embedded in Institutional Activities}

The study contributes to filling the gap identified previously; that there is a lack of indepth studies of students' reasoning on SSIs while working with the Internet, and that investigates the relationship between the institutional setting, the technologies involved, and the interacting participants. In this project, the teachers and researchers created an environment that encouraged students, through digital inquiry and digital mapping tools, to seek and select information, handle the complexities of controversial issues, generate questions, persuade others of their understanding, and engage extensively in collaborative discourse. The study reports how upper secondary school students, having acquainted themselves with food biotechnology online, repeatedly invoke the widespread recirculated online message that GMOs cause cancer in rats in various communicative activities when engaged in mapping socioscientific controversies. By using the notion of CATs, the meaning and function of invocations of science were analyzed in different educational arrangements. This sociocultural approach to studying students' reasoning in different types of conversations with empirical dimensions, such as purposes and tasks and discourse types particular to the type of activity, is relevant for understanding the students' claims. The claims gained its meaning and rhetorical power as a discursive resource intrinsic to different CATs. Hence, disciplinary norms of valid argumentation 
are made manifest in communication in the science classroom, and what students say is not seen to be what they believe irrespective of contexts, but rather as participating accountably.

In this study, I have articulated how the different CATs, deliberative discussion, debate, and seminar enable students to invoke science for different purposes and the kind of communicative skills trained depending on the kind of activity students engage with. In both the debate and the seminar, which were evaluated according to criteria that stress the value of putting forward well-grounded arguments and consideration for the consequences of a conceivable position, students used appeals to science and focused on risk and danger to orientate their arguments accountably.

In the deliberation, students had opportunities to convincingly report others' claims and critically evaluate them. This points to the importance of, when socioscientific controversies are introduced in the classroom, providing students with a possibility to engage in various types of conversations since they cultivate different kinds of communicative competences relevant for citizenship. These communicative activity types are common in project work in school, so these insights are generative also for other contexts arranged in similar ways.

There has been a considerable amount of research conducted on the benefits of introducing SSIs into classrooms (Sadler and Dawson 2012; Zeidler 2014), and it has been argued that inclusion of SSIs in classrooms "provide opportunities for students to reflect on issues in order to evaluate claims, analyze evidence, and assess multiple viewpoints regarding ethical issues on scientific topics through social interaction and discourse" (Zeidler et al. 2009, p. 75). Although some studies have shown that students seldom include scientific knowledge in reasoning SSI activities (Albe 2008), the findings reported in this study are in line with those of previous studies (Orlander Arvola and Lundegård 2012; Nielsen 2012a) which reported how students were able to use science in specific ways that suit their argumentative goals. This study showed similarity to Nielsen (2012a) on how students were able to selectively use science in attempts to frame specific aspects of the issue as the salient aspects, and to make it appear that these aspects call for certain positions to be taken toward it. The students in this study used the science to frame the issue as particularly risky and with unforeseen consequences on health. The explanation for why particular resources are drawn on in communicative situations is different from that of Walker and Zeidler (2007) who interpreted the absence of invocations of science in discussions as a lack of robust cognitive frameworks which resulted in an inability to use science.

In addition, this study showed how the information most prominent online was used for the same purpose, and that questionable, highly controversial scientific results can do the same work as established science. The controversial nature of the science was not made relevant since the purpose was to make accountable contributions: a persuasive argument in a debate and when qualifying a reflective position in a seminar.

\section{A Descriptive Account of an Unfolding Socioscientific Reasoning}

The depiction of the particulars of everyday conditions presented does not suggest ways discussions ought to be, or ways SSI education programs should be, formulated. Rather than showing how students achieve or fail to achieve a standard, I wish to contribute to an understanding of how students interact when SSIs, presented unfiltered on the Internet, are introduced into science classrooms. Descriptions of science classrooms offer empirical examples for discussion of epistemic shifts in studies of cognition and practice from individual minds to communities and groups (Kelly 2008). The methodological and theoretical approach 
to analyzing students' reasoning undertaken in this study enabled me to reveal how making claims and taking a stand regarding SSCs can be seen as being shaped by the framings and demand characteristic of the activity in which students are engaged.

An important and distinctive feature of the validation of discourse work conducted in this article is the presentation of materials in a way that allows readers to evaluate their adequacy allowing for readers' assessment of the particular interpretation that is made side by side with the original materials. Of particular relevance to the aim and research questions of this study, the method has distinct advantages for identifying the influence of contextual factors that cannot be statistically or experimentally controlled for understanding the unique processes at work in specific situations (Maxwell 2004). It has the potential to highlight the importance of the context of the phenomenon studied, and to do so in a way that does not simply reduce this context to a set of "extraneous variables." It relies fundamentally on an understanding of the processes by which an event or situation occurs, rather than simply a comparison of situations involving the presence and absence of the presumed cause. Finally, it legitimates a concern with understanding particular situations and events, rather than addressing only general patterns. Insight into how students draw on science in SSI reasoning is contingent on contextual features is realized in practice, and is only available through empirical analyses of the situated practice.

However, this raises the question considering that study taking a sociocultural and dialogic approach to understanding students' reasoning processes is locally situated: is it then possible to make general claims based on analyses of interactions taking place within a particular setting? The findings are context specific and not generalizable as such, but the findings are also contextualized to such a degree that they are recognizable and thus transferable to other contexts with similar contextual features. Over time, empirical studies from similar educational settings generate robustness and nuances in analytic generalizations that cannot be made from one study alone. This means that over time, we become more sensitive to students' uses of science in SSC reasoning in various settings and topics.

\section{The Persuasive Power of Appealing to Science in SSI Reasoning}

The examples analyzed how invoking science is effective for students in order to engage accountably in the various activities. Discussions of SSIs provide rich opportunities to privilege scientific sources, since there are so many varied arguments from other disciplines such as economy or political science or of emotional, personal, nonscientific nature that teachers might not be familiar with, and that are not attended to in the science curriculum, and thus not made relevant in the classroom. The examples illustrate the persuasive power of the "appeals to science," enlisting scientific objectivity and rigor to underpin the credibility of socioscientific arguments, and conversely point to how an absence of such grounds may be invoked to delegitimize opposition even if there are real political and social implications which are not adequately addressed in a science program. At the same time, to determine questions regarding issues of concern, we know that such issues cannot be simply outsourced to science. Engaging with complex issues online such as food biotechnology is demanding and involves encountering knowledge claims from a variety of fields including science, economics, global perspectives, governance issues, and a variety of stakeholder perspectives. How students frame the issue toward the end of such a project in terms of science or other relevant discourses is interesting. 
Caution must be applied when drawing conclusions from this case study, but the findings support an argument that Feinstein and Kirchgasler (2015) make that it is probable that a science classroom treats SSIs such as climate change in scientific terms not in social or political terms. Based on an analysis of how sustainability is described in the science standards in the USA, they argue that students who are taught to think about sustainability from the perspectives described will be less able to see its ethical and political dimensions and less prepared for the political realities of a society that must balance the needs of multiple groups. It might be brought into question to what extent the introduction of SSIs into science classroom necessarily develops competences, such as addressing knowledge claims from different fields and weighing discourses and identifying restricted or faulty argument, and acknowledging that the knowledge at play is the result of socially constructed investigation processes (cf. Morin et al. 2017). A better understanding of the argumentation as sociocultural activity is called for in order to understand how (whether) science is privileged in classroom discussions of SSIs.

In addition to the privileging of scientific perspective of a complex issue, the study also brings to the fore another problematic aspect of the discourse namely that the scientific evidence provided is not questioned (except in example 2 when students are deliberating, otherwise not in the whole data corpus), rather it is more often established as an indisputable fact. The authority of science is also in this classroom an important legitimizing factor; science was put forward as "an objective and universally applicable basis for rational decisionmaking” (Sykes 2016, p. 499).

\section{Final Remarks and Implications}

Expanding understanding of how students handle information online is highly relevant since teachers can often no longer solely direct students to curated sources such as books, and while they may be able to direct them to what could be considered appropriate websites, it is not likely or perhaps even desirable that students would restrict themselves in this way. Understanding the ways that students work together to navigate online information and the role of teachers and the ways they can help students are important for improving students' competences for engaging in dialogue on such issues. Further investigation is needed to determine how advanced tasks can be scaffolded when SSIs are used to progress student's digital and scientific literacy.

The findings of this study suggest the need for continued efforts to understand if and how activities that handle controversies in science education foster the capacity to engage with others thus providing students with support in handling diversity and complexity when "exposed to the world" (Biesta 2007, 2014) through the Internet. As has already been mentioned, engaging with complex issues online such as food biotechnology is demanding, and involves encountering knowledge claims from a variety of areas including science, economics, global perspectives, governance issues, and multiple stakeholder perspectives. When science students are taught to privilege science in complex Socioscientific Controversies, they may be less able to see relevant ethical and political dimensions and less prepared for the political realities of a pluralist, democratic society. Such students, having learned to make what appears to be well-founded knowledge claims by appealing to science, may also be less prepared for the need to balance the needs of multiple groups and for integrating science with other sources of knowledge to develop appropriate, contextualized responses to complex issues. The solutions to problems for such students would naturally be grounded in what is known and understandable to them, and they would be likely to favor technological change 
over social and political changes. Like many scientists, these students might be too quick to equate resistance to new policies on a scientific or technical innovation to scientific ignorance, rejecting or marginalizing accounts that originate from other disciplines and other cultural perspectives. For example, teaching and learning about agricultural biotechnology for such students would likely focus on questions of health and environmental risk, missing the fact that much resistance to agricultural biotechnology is based on ethical and economic objections.

This article also addresses a problematic aspect of the SSI discourse, when students engaged in SSI practices in science education, such as privileging the scientific perspectives on a complex issue, invoke controversial scientific findings that circulate online as objective "truths" in activity types that make such appeals to science relevant. The findings highlight the importance of addressing the disjunctures amongst the claims made in a scientific journal, how such claims are interpreted in a scientific setting, and the way the claims are recontextualized by interest groups online once stripped of their scientific context. Similar to the argument previously made by scholars in the field of nature of science (NOS) (Bell \& Lederman, 2003), the findings of this study indicate that students' work on SSIs should be accompanied by examination of the ways in which scientific knowledge has been produced within a community. They show that when students search for information and encounter links to scientific articles online they do not necessarily have full access to them, and can be left to work with only the information made available freely online. Providing access to databases of scientific journals in schools would be a good step toward handling critical engagement with science inthe-making.

When working with online material, particularly when handling scientific claims in an historical flow online, there is an opportunity to develop not only digital but also scientific literacy. Many different distinctions need to be made to relate critically to knowledge claims found on the Internet including the "non-science versus science" distinction emphasized in the curriculum. Teachers need to attend to this distinction, but also to others such as the distinction between a single scientific article versus a scientific field, and a relevant distinction in terms of controversies like those surrounding vaccines, GMO, and global warming. The relevance of focusing on this distinction is highlighted by how claims made by students studied in this dissertation who refer to single scientific articles in a scientific field that have long since been refuted are circulating online. Introducing a variety of distinctions has the potential to develop students' competences so that they become more comfortable with contradiction and ambiguity and avoid simply using scientific knowledge to "resolve" the issue at hand. One approach to expanding students' understanding of SSCs is to ask them to engage closely with controversies and to explore and visualize their complexity by embracing differences, seeking to interpret this complexity and communicate it to others. Explicitly acknowledging the complexity of controversies, and asking students to describe and interpret the shifting entanglements of knowledge, is one plausible way forward.

Acknowledgments I would especially like to thank the anonymous reviewers and my colleagues in the Sociocultural and Dialogical Studies seminar who provided comments on earlier drafts of this text. I owe special thanks to professors Åsa Mäkitalo and Thomas Hillman who provided comments and support throughout the research process.

Funding Information Open access funding provided by University of Gothenburg. The research reported is funded by the Swedish Research Council. It has been conducted within the University of Gothenburg LETStudio group and as part of the LinCS research environment, a 10-year funded $\mathrm{CoE}$ for research on learning, interaction, and IT. 


\section{Appendix 1}

[text]Simultaneous/overlapping utterances

(3s)Shows pauses from one second and longer

(.)Pauses shorter than one second

?Marks intonation of a question

TextUnderlining indicates emphasis

$(($ text $))$ Transcribers' commentaries on inaudibility, nonverbal aspects, characterizations of how talk was delivered, and extra discursive activities

text=

$=$ textIndicates latching turns

\section{Appendix 2 Information sheet to students from teachers}

Get the hang of it - Controversy mapping

\section{Description}

Your task will be to investigate your "area" based on a method known as "Controversy mapping." The name implies that the method involves mapping controversies within an area. Thus, it is not a matter of finding one answer but rather exploring different perspectives, divisions and actors in an area.

\section{Purpose}

The purpose of the project is to work with the following objectives from the curriculum: "Students should therefore be given the opportunity to develop an ability to evaluate different types of sources and to distinguish between scientific and non-scientific claims. Students should be given the opportunity to develop interest in science issues. The education should provide an understanding of how mutual science has influenced and influenced each other and, in particular, highlighting the role of science in sustainable development issues. Students will also be given the opportunity for ethical discussions about the role of science in society."

\section{Procedures}

The project will be conducted in various stages - investigation - analysis - role play and seminar:

\section{Investigation}

You will, individually and in groups, map your "area" using the "Controversy mapping" method. You will be introduced in how to use the digital mapping tools and when you get started with the work you will also have access to tutorials. Your searches will generate a physical image, a map, where different actors and how they are linked to each other are displayed. This map will give you "control of" your controversy.

\section{Analysis}

Once you have got your map, it's time to figure out and review the different pages, actors and arguments you have seen. The analysis should be summarized in the form of a shorter PM, which will then be presented orally and an analysis in English. You will analyze both the pro and the cons.

\section{Role Play - Press Conference (Debate)}

Once you have examined the area and analyzed your maps, prepare for a press conference with invited "journalists". During the press conference you will represent one of the actors identified from the map. You and your side of the controversy will then present a picture of the area and be able to answer the journalists' critical questions. 


\section{Seminar}

Here you will have the opportunity to show your knowledge in the entire area that you and your group have investigated. You will also be given the opportunity to reflect on the maps of the other groups and the conclusions they have drawn.

\section{Task 1}

\section{Research}

The purpose of your research is to get a broad picture of the area in question. When you have found your map, you are supposed to analyse it with regard to the following questions:

- Which "sides" are there in the area?

- Who are the contributors? What is their respective position in relation to each other? What connections are there between them?

- What do the arguments on the different "sides" look like? What are these arguments based on? Which or whose interests do the contributors have in mind?

Your thoughts should be summarized on approximately one A-4 page according the the following guidelines:

A short presentation of the area.

Your 'answers' to the questions above.

Summing up and a discussion.

It is important to use a formal language.

\section{Task 2}

\section{Press Conference - Debate}

Now you have gathered a lot of information, arguments and opinions in your area - then it's time to test if this holds. You are now to enact a role (the role will be assigned to you) of one of the actors you have identified in the mapping - you will then prepare for the press conference. You will not know which questions that the "journalists" will ask, but you should be prepared for the following:

How would you describe the area? What is your attitude towards it?

What arguments do you have for your case? What kind of opposing argument do you usually encounter?

What are the consequences of your reasoning in the long term? In short term? Why?

Which interests do you represent? What kind of perspectives?

What are your arguments based on? Why?

\section{Task 3}

\section{The seminar}

In the seminar you will be divided into groups and you will discuss overall questions that concern both the areas (GMO/Fracking) you have had in the class. For this purpose, you should consider the maps produced in both areas

- What constitutes the controversy? Explain by using your map. 
- Who is interested in the existence of a controversy? Who would have an interest in reaching an increased consensus on the issue?

- What does the mapping show?

- Who or whose voices are heard the most? Why is that? Does it differ between the controversies? Between the groups?

- What does the media's role look like?

- Were you surprised by anything when you investigated the actors? Why?

- What have you learned from the controversy mapping? Has the work raised any new questions?

- Are there any issues you think would be interesting to map? Why?

\section{Grading criteria}

\begin{tabular}{|c|c|c|c|}
\hline Content & Acceptable level & Intermediate level & High level \\
\hline $\begin{array}{l}\text { Knowledge about } \\
\text { the significance of } \\
\text { science on } \\
\text { individual and } \\
\text { society. } \\
\text { Ability to use } \\
\text { science to } \\
\text { communicate and } \\
\text { critically examine } \\
\text { and use } \\
\text { information }\end{array}$ & $\begin{array}{l}\text { The student discusses } \\
\text { briefly the questions } \\
\text { concerning science } \\
\text { importance for the } \\
\text { individual and society. } \\
\text { In the discussions the } \\
\text { student can put forward } \\
\text { simple arguments and } \\
\text { briefly for the } \\
\text { consequences of some } \\
\text { conceivable position. } \\
\text { In addition the student uses } \\
\text { different types of sources } \\
\text { and makes relatively } \\
\text { simple evaluations of the } \\
\text { credibility and relevance } \\
\text { of the information and the } \\
\text { sources. }\end{array}$ & $\begin{array}{l}\text { The student discusses in } \\
\text { detail issues that handles } \\
\text { the significance of } \\
\text { science for the individual } \\
\text { and society. } \\
\text { In the discussions the } \\
\text { students put forward } \\
\text { well-grounded arguments } \\
\text { and for the consequences } \\
\text { of a conceivable position. } \\
\text { In addition the student } \\
\text { uses different types of } \\
\text { sources and makes } \\
\text { well-grounded } \\
\text { evaluations of the } \\
\text { credibility and relevance } \\
\text { of the information and } \\
\text { sources. }\end{array}$ & $\begin{array}{l}\text { The student discusses in } \\
\text { detail and nuanced } \\
\text { complex issues } \\
\text { concerning the } \\
\text { significance of science } \\
\text { for the individual and } \\
\text { society. } \\
\text { In the discussions the } \\
\text { student put forward } \\
\text { well-grounded and } \\
\text { nuanced argument and } \\
\text { consequences of several } \\
\text { conceivable positions. } \\
\text { The student even } \\
\text { suggests new positions to } \\
\text { discuss. } \\
\text { In addition the student uses } \\
\text { different types of sources } \\
\text { and makes well-grounded } \\
\text { and nuanced evaluations } \\
\text { of the credibility and } \\
\text { relevance of the } \\
\text { information and sources. }\end{array}$ \\
\hline
\end{tabular}

Open Access This article is distributed under the terms of the Creative Commons Attribution 4.0 International License (http://creativecommons.org/licenses/by/4.0/), which permits unrestricted use, distribution, and reproduction in any medium, provided you give appropriate credit to the original author(s) and the source, provide a link to the Creative Commons license, and indicate if changes were made.

\section{References}

Åberg, M., Mäkitalo, Å., \& Säljö, R. (2010). Knowing and arguing in a panel debate. Speaker roles and responsivity to others. In K. Littleton \& C. Howe (Eds.), Educational dialogues: understanding and promoting educational dialogues (pp.13-30). London \& New York: Routledge.

Albe, V. (2008). When scientific knowledge, daily life experience, epistemological and social considerations intersect: students' argumentation in group discussion on a socio-scientific issue. Research in Science Education, 38(1), 67-90. 
Alessandrini, D. (2010). GMOs and the crisis of objectivity: nature, science and the challenge of uncertainty. Social \& Legal Studies, 19(3), 3-23.

Almqvist, J., \& Östman, L. (2006). Privileging and artifacts: on the use of information technology in science education. Interchange, 37(3), 225-250. https://doi.org/10.1007/s10780-006-9002-z.

Asterhan, C. S. C., \& Schwarz, B. B. (2016). Argumentation for learning: well-trodden paths and unexplored territories. Educational Psychologist, 51(2), 164-187. https://doi.org/10.1080/00461520.2016.1155458.

Beacco, J.-C., Claudel, C., Doury, M., Petit, G., \& Reboul-Touré, S. (2002). Science in media and social discourse: new channels of communication, new linguistic forms. Discourse Studies, 4(3), 277-300.

Biesta, G. (2007). Education and the democratic person: towards a political conception of democratic education. Teachers College Record, 109(3), 740-769.

Biesta, G. (2014). Cultivating humanity or educating the human? Two options for education in the knowledge age. Asia Pacific Education Review, 15, 13-19.

Billig, M. (1996). Arguing and thinking: a rhetorical approach to social psychology. Cambridge: Cambridge University Press.

Buttny, R. (1993). Social accountability in communication. London: SAGE Publications.

Clancy, K., \& Clancy, B. (2016). Growing monstrous organisms: the construction of anti-GMO visual rhetoric through digital media. Critical Studies in Media Communication, 33(3), 279-292.

DeLuca, K. M., \& Peeples, J. (2002). From public sphere to public screen: democracy, activism, and the "violence" of Seattle. Critical Studies in Media Communication, 19(2), 125-151.

Engle, R. A., \& Conant, F. R. (2002). Guiding principles for fostering productive disciplinary engagement: explaining an emergent argument in a community of learners classroom. Cognition and Instruction, 20(4), $399-483$.

Feinstein, N., \& Kirchgasler, K. (2015). Sustainability in science education? How the next generation science standards approach sustainability, and why it matters. Science Education, 99(1), 121-144. https://doi. org/10.1002/sce. 21137 .

Furberg, A., \& Ludvigsen, S. (2008). Students' meaning making of socioscientific issues in computer mediated settings: exploring leaning through interaction trajectories. International Journal of Science Education, 30(13), 1775-1799.

Goodwin, J., \& Honeycutt, L. (2009). When science goes public: from technical arguments to appeals to authority. Studies in Communication Sciences, 9(2), 19-30.

Heath, C., Hindmarsh, J., \& Luff, P. (2010). Video in qualitative research. Analysing social interaction in everyday life. London: Sage.

Hodson, D. (2011). Looking to the future. Retrieved from https://doi.org/10.1007/978-94-6091-472-0.

Hsu, C.-Y., Tsai, M.-J., Hou, H.-T., \& Tsai, C.-C. (2014). Epistemic beliefs, online search strategies, and behavioral patterns while exploring socioscientific issues. Journal of Science Education and Technology, 23(3), 471-480. https://doi.org/10.1007/s10956-013-9477-1.

Jacomy, M., Venturini, T., Heymann, S., \& Bastian, M. (2014). ForceAtlas2, a continuous graph layout algorithm for handy network visualization designed for the Gephi software. PLoS One, 9(6), e98679. https://oi. org/10.1371/journal.pone.0098679.

Jefferson, G. (1984). Transcription notation. In J. M. Atkinson \& J. Heritage (Eds.), Structures of social action: studies in conversation analysis (s. ix-xvi). Cambridge University Press.

Jordan, B., \& Henderson, A. (1995). Interaction analysis: foundations and practice. The Journal of the Learning Sciences, 4(1), 39-103.

Kelly, G. J. (2008). Discourse, description, and science education. In W.-M. Roth \& R. K. Yerrick (Eds.), Establishing scientific classroom discourse communities multiple voices of teaching and learning research (pp. 79-104). New Jersey: Lawrence Erlbaum Associates, Inc.

Kelly, G. J. (2011). Scientific literacy, discourse, and epistemic practices. In C. Linder, L. Östman, D. A. Roberts, P.-O. Wickman, G. Erickson, \& A. MacKinnon (Eds.), Exploring the landscape of scientific literacy. New York: Routledge Taylor \& Francis Group.

Klosterman, M. L., Sadler, T. D., \& Brown, J. (2012). Science teachers' use of mass media to address socioscientific and sustainability issues. Research in Science Education, 42(1), 51-74. https://doi.org/10.1007 /s11165-011-9256-z.

Latour, B. (1987). Science in action. Cambridge, MA: Harvard University Press.

Levinson, S. (1979). Activity types and language. Linguistics, 17, 365-399.

Levinson, R., \& Turner, S. (2001). Valuable lessons: engaging with the social context of science in schools. London: Wellcome Trust.

Linell, P. (1998a). Approaching dialogue: talk, interaction and contexts in dialogical perspectives. Amsterdam: Johns Benjamins.

Linell, P. (1998b). Discourse across boundaries: on recontextualizations and the blending of voices in professional discourse. Text, 18, 143-157. 
Linell, P. (2009). Rethinking language, mind and world dialogically. Charlotte, NC: Information Age Publishing, Inc.

Linell, P. (2010). Communicative activity types as organisations in discourses and discourses in organisations. Discourses in Interaction, 203, 33-60.

Mäkitalo, Å. (2006). Effort on display: unemployment and the interactional management of moral accountability. Symbolic Interaction, 29(4), 531-555. https://doi.org/10.1525/si.2006.29.4.531.

Mäkitalo, Å., Jakobsson, A., \& Säljö, R. (2009). In K. Kumpulainen, C. Hmelo-Silver, \& M. Cesar (Eds.), Investigating classroom interaction. Methodologies in action (pp. 7-26). Rotterdam/Taipei: Sense Publishers.

Marková, I., Linell, P., Grossen, M., \& Salazar Orvig, A. (2007). Dialogue in focus groups: exploring in socially shared knowledge. London: Equinox.

Mason, L., Ariasi, N., \& Boldrin, A. (2011). Epistemic beliefs in action: spontaneous reflections about knowledge and knowing during online information searching and their influence on learning. Learning and Instruction, 21(1), 137-151. https://doi.org/10.1016/j.learninstruc.2010.01.001.

Mason, L., Scrimin, S., Tornatora, M. C., Suitner, C., \& Moè, A. (2018). Internet source evaluation: the role of implicit associations and psychophysiological self-regulation. Computers \& Education, 119, 59-75. https://doi.org/10.1016/j.compedu.2017.12.009.

Maxwell, J. A. (2004). Causal explanation, qualitative research, and scientific inquiry in education. Educational Researcher, 33(2), 3-11. https://doi.org/10.3102/0013189X033002003.

Mercer, N. (2004). Sociocultural discourse analysis: analysing classroom talk as a social mode of thinking. Journal of Applied Linguistics, 1(2), 137-168.

Moloney, M., et al. (2012). UK Plant Scientists call on Europe to change current laws and adopt science-based GM regulations. Retrieved from http://www.ipetitions.com/petition/changeeugmlegislation/signatures/page/8

Morin, O., Simonneaux, L., \& Tytler, R. (2017). Engaging with socially acute questions: development and validation of an interactional reasoning framework. Journal of Research in Science Teaching, 54(7), 825851. https://doi.org/10.1002/tea.21386.

Nestle, M. (2010). Safe food: the politics of food safety. Retrieved from http://ebookcentral.proquest. com/lib/gu/detail.action?docID $=566760$

Nielsen, J. A. (2012a). Co-opting science: a preliminary study of how students invoke science in value-laden discussions. International Journal of Science Education, 34(2), 275-299.

Nielsen, J. A. (2012b). Science in discussions: an analysis of the use of science content in socioscientific discussions. Science Education, 96(3), 428-456. https://doi.org/10.1002/sce.21001.

Nowotny, H. (1981). Experts and their expertise: on the changing relationship between experts and their public. Bulletin of Science, Technology \& Society, 1(3), 235-241.

Orlander Arvola, A., \& Lundegård, I. (2012). 'It's her body'. When students' argumentation shows displacement of content in a science classroom. Research in Science Education, 42, 1121-1145.

Potter, J. (1996). Representing reality. Discourse, rhetoric and social construction. London: SAGE.

Rudsberg, K., \& Öhman, J. (2015). The role of knowledge in participatory and pluralistic approaches to ESE. Environmental Education Research, 21(7), 955-974.

Sadler, T. D., \& Dawson, V. (2012) Socio-scientific Issues in Science Education: Contexts for the Promotion of Key Learning Outcomes. In B. Fraser, K. Tobin, C. McRobbie (Eds.), Second International Handbook of Science Education (pp. 799-809). Dordrecht: Springer.

Sanchez, M., \& Parrot, W. (2017). Characterization of scientific studies usually cited as evidence of adverse effects of GM food/feed. Plant Biotechnology Journal, 15, 1227-1234.

Séralini, G.-E., Clair, E., Mesnage, R., Gress, S., Defarge, N., Malatesta, M., Hennequin, D., \& de Vendômois, J. S. (2014). Republished study: Long-term toxicity of a RoundUp herbicide and a RoundUp-tolerant genetically modified maize. Environmental Sciences Europe, 26(1), 1-17. https://doi.org/10.1186/s12302014-0014-5.

Solin, A. (2004). Intertextuality as mediation: on the analysis of intertextual relations in public discourse. Text Interdisciplinary Journal for the Study of Discourse, 24(2), 267-296.

Solli, A., Mäkitalo, Å, \& Hillman, T. (2018). "Rendering Controversial Socioscientific Issues Legible through Digital Mapping Tools." International Journal of Computer Supported Collaborative Learning 13(4),391-418.

Sykes, K. (2016). The appeal to science and the formation of global animal law. European Journal of International Law, 27(2), 497-518. https://doi.org/10.1093/ejil/chw013.

Tsai, C.-Y. (2018). The effect of online argumentation of socio-scientific issues on students' scientific competencies and sustainability attitudes. Computers \& Education, 116(Supplement C), 14-27. https://doi. org/10.1016/j.compedu.2017.08.009.

Venturini, T. (2010a). Building on faults: how to represent controversies with digital methods. Public Understanding of Science, 21(7), 796-812. 
Venturini, T. (2010b). How to represent controversies with digital methods. Public Understanding of Science, 21(7), 796-812.

Walker, K. A., \& Zeidler, D. L. (2007). Promoting discourse about socioscientific issues through scaffolding inquiry. International Journal of Science Education, 29(11), 1387-1410.

Walsh, E., \& Tsurusaki, B. (2018). "Thank you for being republican": negotiating science and political identities in climate change learning. The Journal of the Learning Sciences, 27(1), 8-48.

Wertsch, J. V. (2007). Mediation. In H. Daniels, M. Cole, \& J. V. Wertsch (Eds.), The Cambridge companion to Vygotsky (pp. 178-192). New York: Cambridge University Press.

Zeidler, D. L. (2014). Socioscientific issues as a curriculum emphasis. Theory, research and practice. In S. Abell \& N. Lederman (Eds.), Handbook on research in science education (Vol. 1-II, s. 697-726). New York: Routledge.

Zeidler, D. L., Sadler, T. D., Simmons, M. L., \& Howes, E. V. (2005). Beyond STS: a research-based framework for socioscientific issues education. Science Education, 89(3), 357-377.

Zeidler, D. L., Sadler, T. D., Applebaum, S., \& Callahan, B. E. (2009). Advancing reflective judgment through socioscientific issues. Journal of Research in Science Teaching, 46(1), 74-101.

Publisher's Note Springer Nature remains neutral with regard to jurisdictional claims in published maps and institutional affiliations. 